\title{
Challenges in training teacher-librarians at the Department of Information Studies, University of Natal, Pietermaritzburg
}

\author{
THULI RADEBE \\ University of Natal, Department of Information Studies, P/B \\ X01, SCOTTSVILLE, Pietermaritzburg, South Africa, 3209, \\ e-mail: radebe@infs.unp.ac.za
}

\begin{abstract}
The paper raises problems which are experienced by the Department of Information Studies in running the Diploma in School Librarianship (DSL). These problems relate to obstacles which interfere with attracting students into the program and getting them committed to school librarianship as a profession, and also relate to inadequacies which students bring into the program. The problems, which are outlined from observations made by faculty members in the Department, are reinforced by some literature findings. A few solutions, as attempted by the Department, are also discussed.
\end{abstract}

\section{Introduction}

This paper is based on observations by the presenter, who co-ordinates the Diploma in School Librarianship (DSL), and by other faculty members in the Department of Information Studies, of students who register for this diploma from year to year. Some literature is used to reinforce the discussion of problems.

\section{The DSL}

The DSL is offered full-time over one year, and part-time over two years, to teachers who already have a three-year teaching diploma and a minimum of three years teaching experience. Teachers who already possess a degree occasionally register for the diploma. It was first offered in 1983 at the request of the previously white Natal Education Department (NED), who intended to have people trained and obtain formal qualifications in school librarianship. This way they would be able to develop fully the resource center. The NED ruled that for these teachers to qualify for an extra notch and advancement within the department, the Diploma should be under the Department of Education in the previous Education Faculty. As it happened, only about 4 students from the NED were trained, the bulk of the students being from the previous House of Delegates (for Indians) and black teachers from the previous black departments of education. For the first time, in 1998, the Diploma was offered by the Department of Information Studies in the Faculty of

Education for All: Culture, Reading and Information, IASL, 1998 
Social Science. It became essential to fight for the Diploma to belong to the Department of Information Studies for it to receive the attention and priority it deserves.

Despite the problem of lack of funding to address the massive backlog in school library provision there is an outcry for qualified teacher-librarians in South Africa who will at least help lobby for school libraries to be considered by the decision-makers. According to the Education Foundation (1997), only 4638 out of 27188 (17\%) have school libraries.

\section{Challenges}

One challenge faced by the Department of Information Studies in offering the DSL is that of attracting teachers into the program whose objective is to stay in the school librarianship profession when they qualify, and also of persuading to stay in the same profession those teachers who intend to use the DSL to achieve other goals. Another challenge surfaces in the actual training once the students have been accepted. The challenges are, therefore, discussed in two categories, namely those which manifest themselves in attracting students into the diploma and motivating them to stay in the profession (discussed under motivation) and those which manifest themselves when teaching the students, that is, what students bring into the lecture room.

\section{Motivation}

Many of the applicants who enter the DSL program are not driven by interest in, or a commitment to, school librarianship, but by other ambitions outside the school librarianship profession. The first ambition achieved through the DSL is:

\section{Higher salary notches and promotions}

For a long time it was normal practice for some, if not all, education departments in South Africa to award teachers with promotions and higher salary notches when they produced their diploma certificates, regardless of whether or not they were using their newly-acquired qualification to start and/or to run school libraries. This ambition, which is expressed by students when they are interviewed for selection into the DSL, led to a situation where three or four teachers in one school would achieve the same diploma. On producing the certificate to the respective departments of education they would all be automatically awarded higher salaries, even with only one of them running the library and the others happily continuing with normal teaching activities that they were engaged in before they earned the DSL. Croup thinking amongst many teachers also plays a role in perpetuating this situation, so that if one teacher gets a higher qualification it becomes everyone's objective to do the same.

The DSL is not the only victim of this ambition, but people in the teaching profession in education also express disillusionment at this mentality of more diplomas and certificates for promotion and higher salary notches at the expense of pupils. For instance, Tiley (1993:32-33) accused the "disease of certification" which comes with grading for causing many problems such as teacher absences as they pursue their studies which become their first priority, to the detriment of the pupils. Babaleye (1998:25), although referring to the situation in Nigeria, also complains of their educational system which puts so much emphasis on paper qualifications for jobs. How can students be convinced that higher 
salaries and promotions should not be given more priority than the improvement of their performance when they complete the diploma? This issue will be discussed later.

\section{Bachelor of Education (B.Fd.)}

Another important attraction into the DSL program for local teachers who do not have a degree is that it secures them an entry requirement for the Bachelor of Education (B.Ed.) degree. At Natal University the B.Ed, which is a postgraduate honors degree for teachers has, since 1997, been available to those who have an $M+4$ (Matriculation plus a four-year tertiary qualification), regardless of whether or not they hold a degree. That means that those teachers who have a three-year teaching diploma after matriculation need another one-year diploma which will elevate them to the $M+4$ level and secure them an entry into the B.Ed. The DSL has fallen prey to some of those teachers whose ultimate objective when they complete it is to qualify for the B.Ed. It is in this situation that the DSL is exploited to serve as a conduit to the B.Ed. degree. This was expressed by students when they were interviewed for entry into the DSL in 1998.

The Department of Information Studies' disadvantage when compared with the requirements for the $B$.Ed. is that it does not allow registration for postgraduate degrees to non-graduates.

\section{Avoiding the classroom}

Some teachers study for the DSL to avoid or to get out of the classroom which has become, and is still becoming, more rigorous and complex. Again, this is expressed by students at the application stage for entry into the program.

With changes in the South African political and educational situations, learners have become aware of their educational rights and have become more demanding and mature in terms of their learning needs. Conversely, those teachers who come from the "old school" of thought are too set in their former ways to cope with these learners. The Outcomes-based Education (OBE), which is being implemented for the first time in 1998, has also brought with it many misgivings for some teachers. As they feel intimidated and threatened they will pursue any course which leads them out of the classroom. It is this naivete, that is, that the library will get them away from the classroom, which attracts some teachers to the DSL program. The book-based and teacher-based type of education was the easiest, because the teacher did not need to be knowledgeable and had full control of the learning process, with rote-learning being practiced. The outcomes-based education, with its materials-based and learner-centered approach, is a great burden to most teachers. This illustrates the point which was made by Brown (1990:23) that uncertainty about the "technical culture and one's ability to help students leads teachers to be on the defensive because their self-esteem is threatened. We avoid situations where our performance adequacy, and thus our sense of self-esteem, may conceivably be called into question."

Getting students to understand that the DSL prepares them for even more involvement, not only in their own classrooms but in their colleagues' classrooms as well, without deterring them from the diploma, is a great challenge. 


\section{Easy option}

Related to the foregoing problem is the misconception that running a school library is an easier option than teaching. Those teachers who are looking for an easier option view the DSL as a way of getting that lighter load. This viewing of teacher-librarianship as an easier option was reported by Charlton (1985:121). This, again, is admitted by many students when they are interviewed for selection into the DSL.

In a nutshell many students are attracted to the program for reasons other than commitment to the school librarianship program.

\section{What students bring to the program}

Once the students are accepted into the DSL, over and above the fact that many have no idea what they are letting themselves in for, the disadvantages and under-preparedness which they bring into the program pose another serious challenge. It is only fair to point out at this stage that a handful of students manage normally, especially some of those who already possess a teaching degree. The first problem manifests itself in the form of a vicious circle.

\section{The vicious circle}

Because of the past education system the Department of Information Studies is confronted with students who, throughout their education, have not had their mental models (previously constructed understandings from which learners draw to make decisions in learning) nurtured and so are bringing nothing or very little into the lecture room. Pitts (1995:180) in her study on information-seeking activities of students in libraries identified incomplete subject-matter mental models, limited subject-matter models and inaccurate adult mental models as leading to incomplete, limited and inaccurate models of information seeking and use activities of students. In the case of the majority of DSL students there is a total lack of these mental models or strands of information from previously constructed understandings to solve problems they are confronted with in their learning tasks (Pitts 1995:179). This, of course, was a deliberate objective of planners of the past education system for blacks. Therefore, most of what they are exposed to in the diploma is new to them---that means that they do not have a knowledge base, because of the rote learning they were exposed to. As we know, mental models are important for providing knowledge and information which serves as a base from which they can borrow, transfer information or make their own inferences. The problem is exacerbated by the fact that these students are also lacking in many learning skills essential to that process, including all information skills. Behrens (1995:258) summed up the problem when she noted that "...many South African students lack the qualities of independence, of self-direction and even of simple curiosity in their attitudes to learning." She further described them as spoon-fed, uncritical, and as a result mentally lethargic students who are not prepared for learning. Helping these students overcome these problems and nurturing their mental models when they should be exploiting them is a major challenge.

\section{Colleges of education-Teacher-training}

The problems outlined above are traceable to the schooling system, as well as to the teacher-training institutions. The majority of black colleges of education have not been, 
and are still not doing, a good job. The majority of teachers are thus under skilled, while many remain unskilled.

Flanagan (1992/93:35) observed that initial training of DET teachers is often unsatisfactory, with courses offering inadequate education theory and inappropriate teaching methods. She further asserted that in black colleges of education, if not in the others in South Africa, student teachers are not generally encouraged to think critically about their courses either during the course or during assessment, because the philosophy of Fundamental Pedagogics, widespread in these colleges of education, discourages a critical stance. This is understandable since, as Amuzu (1992:133) put it, candidates who enter colleges to train as teachers often have low grades in their matriculation examinations as they generally fail to get matriculation exemption to enter the university. In a number of cases students are said to have forced their entry into colleges of education.

Related to this problem is that of lack of understanding of the cognitive process by the majority of teachers because of the rote learning they were exposed to during their own education and training. One of the professional competencies given by the Association for Teacher-Librarians in Canada (1997:3) is that the teacher-librarian understands students and their social, emotional, and intellectual needs-meaning that he or she should understand child and adolescent growth and development for the age levels of the school. Unfortunately DSL students who are already teachers do not understand the developmental milestones' process and they thus resort to the same spoon-feeding of learners, Thus perpetuating rote learning, as was pointed out by Blacquiere (1989). In rote learning things are not put in their right practical perspective. It has been observed that DSL students do not understand the child, the developmental stages and their dynamics, the individuality of each child and the implications thereof for learning. This becomes apparent in the Readership Course, which includes children's literature as well. Flanagan (1992/93:35) blamed the way in which the majority of primary school teachers were trained for $25 \%$ of African children in South Africa growing up to be illiterate, which corresponded with Rogers' conclusion (1994:55) (although he was not referring to the South African situation) that the deficiencies in teachers were at least partly the result of the way teachers were trained. Read Educate and Develop (READ) (1993:2) summed it up well when they stated that the professional training of black teachers had not stressed the importance of reading, or equipped them to involve pupils in the learning process.

\section{Poor command of the English language}

To all the teachers who come into the program English is not only a second language but, as with everything else, the wrong teaching methods, based on wrong policies, were employed in teaching them English. This was supported by Cachalia (1995:152) in stating that "...the language policy implemented in African schools in particular had been detrimental to the development of a child's cognitive and creative skills," further pointing out that pupils' difficulties were compounded by poor language teaching from inappropriately qualified teachers (Cachalia 1995:155), another area in which the vicious circle manifests itself.

\section{The reading culture}

The reading habit is totally lacking in the majority of teachers who register for the DSL. Turning them into readers who can use libraries to inculcate the reading habit in learners is 
another challenge. What is most difficult is the fact that the majority of the students have never read a children's book except for one or two who might be working with the READ classroom library (Radebe 1996). In a situation like this how does one, at this stage and age, provide these teachers with the experience of children's and youth books? Where does one start talking about the setting and characterization (protagonists) when one still has to make them read these books. The Association of Teacher-Librarians (1997:5) gives, as one of the professional competencies for teacher librarians "...developing and promoting the effective use of informational and imaginative resources in all formats...", an example of this being the promotion of voluntary reading throughout the school. Not only do these teachers not have the reading habit but a deeper problem arising from the foregoing is that they are poor readers too, as was pointed out by Blacquiere (1989), which means one cannot expect them to read a book quickly, especially as they have not learnt to enjoy reading books. Remember there are only a limited number of lectures in a semester!

\section{Education without school libraries}

The problem of lack of school libraries in South Africa is well documented (Education Foundation 1997; Stadler 1993; Radebe 1997). As reported earlier the Education Foundation (1997) has estimated that only $17 \%$ of schools in South Africa have school libraries.

The majority of the DSL students have come through a system which was devoid of school libraries and through a teacher training system which did not acknowledge the role and importance of school libraries. Students qualify as teachers without any exposure to libraries, as their lecturers had not experienced libraries themselves. Courses which are aimed at introducing student teachers to the world of libraries are given ancillary status (Majaja 1994; Pholosi 1994). Getting the students to understand the role and objectives of the school library and getting them to integrate the library into the curriculum is an important challenge. Getting them to merge the objectives of the school library with those of the curriculum is another challonge.

\section{Lack of libraries at their schools}

How can these students be motivated to stay in the profession when they do not have libraries to go back to when they qualify? This problem was highlighted in the results of a survey the present author conducted of past students who had completed the DSL, on the problems facing them in the work situation. Twenty seven percent $(27 \%)$ of the respondents whose schools did not have libraries reported that they had felt helpless and had, as a result, abandoned the idea of striving for libraries and concentrated on teaching (Radebe 1997).

\section{Lack of recognition and appreciation for the school library}

It saddens the Department of Information Studies to hear how already qualified teacher-librarians are disillusioned because they have to struggle for recognition in their schools. Again this explains the helplessness expressed by the $27 \%$ of the respondents, as reported above. The biggest challenge and frustration expressed by teacher-librarians in the survey by Radebe $(1997: 224)$ lies in the ignorance of the majority of education professionals and principals regarding the role of libraries in ensuring an excellent 
education. Furthermore, $61 \%$ of the respondents in the present author's survey reported no support from their principals in their fight for school libraries. This lack of support was evidenced in various ways such as the viewing of libraries as a waste of resources and the library being used for other reasons such as meetings. The ignorance of the authorities comes from the situation of libraries not forming part of the initial teacher-training which they have all gone through.

This problem was raised by Tawete $(1988 ; 1991)$ and Olon (1993). Kolasch (1992), Mbambo (1990) and Radebe (1997) had referred to the self-reinforcing cycle, which clearly characterized the situation in South Africa in which teachers-in-training, who have not experienced libraries throughout their schooling, do not utilise a college library, resulting in libraries remaining peripheral to their teaching. Valentine and Nelson (1988) also remarked on teachers' lack of effective library-use skills.

Surely, when these teacher-librarians express this frustration to their colleagues, it cannot be good publicity for the DSL in terms of prospects, since the Department has relied to some extent, on past students passing on the good word and recruiting for the Department. Some good comes out of this because those who are genuinely committed still pursue the Diplona.

\section{Computer literacy}

No teacher-librarian trainer today would let students graduate without computer literacy. The Diploma offers a computer literacy course. By the time they leave they are fully computer literate and have basic understanding of computer applications in school libraries (experts are employed for this). Unfortunately, they go back to situations where there are no computers, even for the administration of the school.

\section{Balancing between prepared and under-prepared students}

Some students, although very few, will have experienced a school library and have internalized the reading habit, and every year a handful will already have a degree. Some will have gained this knowledge and related skills from their involvement with the READ Educational Trust (READ). The great challenge in this case is in satisfying both groups, in terms of maintaining simplicity which can be understood by stragglers and sophistication and complexity and challenge for the more prepared and advanced students.

\section{Demoralized self-concept}

The present author has made an observation (Radebe 1994; 1996; 1997) that the teacher-librarians come into the program with a demoralized self-concept, resulting from the past dispensation. As Amuzu (1992) indicated, many of these teachers entered teaching as a last resort, having not attained sutficient grades to gain entry into universities and are thus already discouraged. As he asserts, from the outset many of them start their training with two serious handicaps, that is, inadequate background and insufficient motivation, which few of them manage to overcome before the end of their training. It is true that many teachers entered the teaching profession by default "...some students went to colleges not because they liked teaching, but because they had nothing else to do" (Salmon and Woods 1991:20). The challenge is in cultivating a positive self-concept in these adults and in helping them regain confidence in themselves, attributes which are so essential for confronting unwilling principals and colleagues and authorities who do not 
appreciate the library and its value. How does one achieve this with these people, in whom a measure of negativity has been instilled all their lives, and some of whom have merely stumbled into the teaching profession?

\section{Marketing strategies}

Stevenson (1987) raised a problem related to the foregoing, when he concluded that teacher-librarians were often not trained in assertive marketing techniques. He expressed the need for courses in marketing strategies. Radebe $(1994 ; 1997)$ emphasized this point. What exacerbates the problem is that students who register for the diploma were not instilled with an enterprising spirit because that was not an objective of the past education system. Instilling an enterprising spirit in the teachers would have clashed with the type of education they were trained to transmit to the pupils. The need for more skills for dealing with unwilling principals and colleagues and authorities was expressed by past students who were already qualified as teacher-librarians (Radebe 1997). How does one nurture an enterprising and a marketing spirit at this stage and age when it entails equipping students with something that they should already be nurturing in their pupils?

Some of the competencies of teacher-librarians, as outlined by the Association for Teacher-Librarianship in Canada (1997), are that the teacher-librarian places priority on staff relationships and leadership in the implementation of change, including keeping abreast of, and communicating, developments in curriculum, instructional strategies and newer information technologies. Getting students to the point where they can be catalysts for change, even in curriculum and policy-related matters, is an awesome challenge since teachers are neither informed on, nor involved in, these matters.

To attempt to rectify all the above in one year is a daunting task-where does one begin?

\section{Change and leadership skills}

Jean Brown (1990:21) made the case for a need for strong leadership and for teacher-librarians to be agents of change and to be involved in preparing students for survival in an information society. Brown (1990) quoted Joyce and Showers whose work shows that, even after teachers are aware of new ideas and have gained intellectual understanding of them and how they can be used in the classroom, they still need help in acquiring the skills to integrate these ideas into their classroom work. The role of the teacher-librarian is very important in providing that type of assistance. Brown (1990) further talked about an educational innovation as a complex process which for implementation will require some classroom teachers to learn how to use a wide range of resources effectively, to plan to team-teach and to allow students more control over learning than perhaps they had before. This corresponds with what is supposedly required of teachers in South Africa for the successful implementation of the newly implemented Outcomes-based Education (Faasen \& Metcalfe 1997). This role was emphasized by the Association of Teacher-Librarians in Canada (1997). Leadership, according to Brown (1990), means vision, values, enthusiasm, trust. It means listening, coaching, effectively wandering around. The students in the DSL program have to play this role, especially in the case of outcomes-based education. The challenge is to equip them with what it takes to be able to play this daunting role. 


\section{Lack of study leave and transfer facilities}

Whilst the education system is undergoing transformation under the new government, leave of absence with full pay has not been granted in the last two years for teachers to study full-time. Teachers cannot sacrifice their salaries and take unpaid study leave, especially as there is also the threat of retrenchment. One has to acknowledge the many problems facing the national education department. As a result, the Department of Information Studies has lost its full-time student population from outside of the city of Pietermaritzburg and only have the part-timers, who do the diploma over two years. Some of these part-time students undertake distances or journeys of up to two hours one way to attend lectures, sometimes three times a week. This is because the transfer facility, which made it possible for teachers to relocate to schools nearer training facilities, has also been done away with.

Some problems outlined in the foregoing discussion cannot be solved by the Department of Information Studies because they are not of the Department's own making, neither are they within the Department's control, although every effort is made to solve these challenges. These efforts or solutions are outlined below.

\section{Solutions}

To fight the promotions and higher salaries syndrome, the Department of Information Studies raised the issue with a local school inspector two years ago. He subsequently devised a system whereby students were not rewarded for their qualifications unless they produced evidence that they were using their diploma, even if to start a usable book-collection somewhere. The students were then forced to start using their newly-acquired skills. The inspector would then be invited by the teacher-librarian to view what they were doing and subsequently the person would be awarded a salary notch. While the Department was still celebrating that achievement, the B.Ed problem materialised and the Department has, as yet, not been able to solve this problem.

The initiative with the inspector was at a local level but the Department is pleased that the new National Department of Education has formalized that system across the board, by ruling that teachers should not be awarded higher salaries and higher positions on producing certificates and diplomas. Higher salaries and ranks will be based on evaluation of an individual's performance and extra effort has thus become important. A few past and present students have said that the DSL has equipped them to perform better.

In an attempt to provide students with some background information to nurture their mental models the Department has made the students' own past experiences as pupils, as student-teachers and as teachers the starting point, no matter how simple and impoverished those experiences are. This has helped bring enough practicality into many of the courses to make the theory understandable/accessible to the students. This makes it easier for students to relate what is transmitted to them to real-life classroom situations. Maintaining a balance between theory and practical situations becomes essential.

Making the courses interesting and placing the knowledge gained in the context of the students' classrooms by using their experiences as the Department's springboard seems to be working to a large extent, in making students discover the school librarianship profession and in convincing them to stay in the profession. Seventy three percent $(73 \%)$ of 
the respondents in the survey conducted by the present author who did not have libraries at their schools reported that they had initiated library-related projects such as starting classroom collections or soliciting READ's involvement. These could be regarded as "success stories." Contact is kept with some of the past students and in a number of cases they pursue this contact. This initiative, plus instilling in students a sense of improvising, helps lessen the problem of lack of libraries at their schools as they start their corner collections and get involved with organizations such as READ.

To address the demoralized self-concept and to empower students to come out of their shells and mingle with other people, the Department encourages students to participate in workshops and seminars, either as presenters or attendants; they are involved in presentations by visitors and encouraged to engage with those visitors and to share experiences and, where possible, materials, with them. This helps them see themselves as part of a "normal" community of librarians who have something valuable to offer. Marketing and public relations form a strong component of the Management course to help them gain assertiveness.

The Department insists on students forming relationships with many willing previously-advantaged schools which are committed to sharing knowledge and experience and sometimes materials, with them. In the "bad old days" of apartheid forming these relationships was easy when schools for different race groups had different terms and the Department could place students in previously-advantaged schools for fieldwork, without taking part-time students away from their classrooms during term-time. Many of these schools encouraged positive exchanges and sharing with those students. The present author is often called in to assist a student transport boxes of donations from some of these schools to their own schools.

Now that terms have been aligned so that all schools in each province, excluding private schools, close on the same day, the students cannot easily be placed in these schools any more. Nevertheless a special program is put together by a local public library, in consultation with the Department, for the July vacation. Since the library has a few branches, including a school projects library for scholars, they are able to organize a variety of programs for DSL students.

The DSL program has a strong component of children's literature which requires students to read as many children's books as possible, as well as review and evaluate them. This helps instill a reading habit in teachers and it is rewarding to see students becoming absorbed in experiencing and discussing children's books. Various programs for instilling a reading habit are discussed at great lengths. A local publishing company, Shuter and Shooter, donated a model children's library a number of years ago and this library has grown as one colleague in particular, Dr Christine Stilwell, who specializes in children's literature, continues to purchase books. This library plays an important role in the DSL program, especially in terms of providing children's books.

To address library literacy amongst student-teachers the Department works closely with some teacher-trainers and is forging relations with colleges of education (whose closure is being celebrated prematurely) for which some Departmental staff serve as external

1 The Read Educate and Develop Trust is a non-governmental organization which is involved in inculcating a reading habit in South African schools. 
examiners and some of whom have solicited staff involvement in curriculum-related discussions.

To maintain a balance between prepared and under-prepared students the Department encourages students to form groups which are mixed in terms of capability and experience, and to change around. The Department also gives advanced students more responsibilities without estranging the stragglers.

The South African education system is undergoing a major transformation which is, at the moment, confused, confusing, demoralizing and accompanied by major funding and embezzlement problems. But we have to make sure that when things begin to improve school libraries will be on the agenda.

\section{Conclusion}

In conclusion the present author can only state that the Department of Information Studies is holding discussions with the KwaZulu-Natal Director of school libraries to find ways of solving some of the problems outlined in this paper, such as those relating to leave of absence for teachers to study full-time.

\section{References}

Amuzu, K. (1992). The role of English in education in the New South Africa. English Usage in Southern Africa, 23, 129-141.

Association for teacher-librarianship in Canada. (1997). Students' information literacy needs in the 21 st Century: competencies for teacher-librarians.

Http://www.sbe.saskatoon.sk.ca/ atlc/competen.htm

Babaleye, T. (1998). Creating a reading culture for Nigeria: breaking the vicious circle of poor education and illiteracy. Development and Cooperation, 1, 25.

Behrens, 5.). (1995), Lifelong learning in the new education and training system. Mousaion, 13(1\&2), 250-263.

Blacquiere, A. (1989). Reading for survival: text and second language students. South African Journal of Higher Education, 3(1), 73-82.

Brown, Jean (1990). Navigating the 90's - the teacher-librarian a change agent. Emergency Librarian, 18, 19-28.

Cachalia, N. (1995). A survey of Johannesburg English teacher's opinions on a language policy for education in a post -apartheid South Africa. Perspectives in Education. $16(1), 147-162$.

Charlton, D. (1985). It shouldn't happen to a librarian. School Librarian, 33, 121-122.

Education Foundation. (1997). EduSource Data News, 17, 3.

Faasen, N. \& Metcalie, L. (1997). Curriculum 2005: a new challenge to resource managers. Cape librarian, July/August, 7-9.

Flanagan, W. (1992/93). Reading programmes: are they the best form of intervention in our schools? Perspectives in Education, 14(1), 35-45. 
Kolasch, M. May (1992). The school year that was. Wilson Library Bulletin, 68, 70 \& 132.

Majaja, V.V. (1994). An analysis of the curricula of school librarianship programmes in colleges of education in Transkei, Venda, Bophuthatswana and Transkei. MIS thesis. Pietermaritzburg: University of Natal, Department of Information Studies.

Mbambo, B. (1990). Librarianship as a component of teacher education. Zimbabwe Librarian, 22(12), 11-13.

Olën, S.I. (1993). Utilization and perceptions of the school library media centre. South African Journal of Library and Information Science, 61(1), 35-42.

Pholosi, T.J. (1994). The effects of teacher-librarianship training at the colleges of education in the former Transkei on school libraries. MIS thesis. Pietermaritzburg: University of Natal, Department of Information Studies.

Pitts, J. M. (1995). Mental models of information: the 1993-94 AASL/Highsmith Research Award study. School Library Media Quarterly, 23, 177-184.

Radebe; T. (1994). Training school librarians in South Africa: a personal view. Innovation, 9, 43-47.

Radebe, T. (1996). The school library movement in South Africa: recent policies and development. In S. A. H. Abidi (Ed.), School libraries in Uganda: papers and proceedings of a DSE/EASL/MOES Seminar, Kampala, 20-25 November 1995 (pp.43-76). Bonn: German Foundation for International Development.

Radebe, T. (1997). Experiences of teacher-librarians in the workplace after completion of the school librarianship programme. South African Journal of Library and Information Science, 65(4), 218-226.

READ Educational Trust. (1993). Annual review. Johannesburg.

Rogers, R. (1994). Teaching information skills: a review of the research and its impact on education. London: Bowker-Saur.

Salmon, C. M. R. and Woods, C. (1991). Challenges of education: challenging the clichè. Durban: University of Natal, Education Research Unit.

Stadler, C. (1993). School libraries in South Africa. Durban: University of Natal, Education Policy Unit (EPU working paper no.2).

Stevenson, J. (1987). How others see us: student teachers' perceptions of school libraries. International Review of Children's Literature and School Librarianship, 2, 10-21.

Tawete, F.K. (1988). The challenge of libraries in the Third World. Libri, 38(4), 330-339.

Tawete, F.K. (1991). The plight of school libraries in Africa. Information Trends, 4(3), 123-138.

Tiley, J. (1993). Upgrading is getting us down. Educamus, 39(1), 32-33.

Valentine, P. \& Nelson, B. (1988). Sneaky teaching: the role of the school librarian: teachers' and school librarians' perceptions. London: British Library Board. 